\title{
Temporal Artery
}

National Cancer Institute

\section{Source}

National Cancer Institute. Temporal Artery. NCI Thesaurus. Code C33741.

A terminal branch of the external carotid artery that branches into the anterior and posterior temporal arteries. 